\title{
Complex Vegetation Survey in a Fruit Plantation by Spectral Instruments
}

\author{
Péter Riczu ${ }^{1}$, Attila Nagy ${ }^{2}$, Éva Bozsik ${ }^{3}$, Bernadett Gálya ${ }^{4}$, Péter Ákos Mesterházi ${ }^{5}$, János Tamás ${ }^{6}$
}

\section{IN F O}

Received 18 Nov. 2013

Available on-line 31 Dec. 2013

Responsible Editor: Rajkai, K.

Keywords:

intensive apple orchard, GreenSeeker 505 vegetation indexmeter, Tetracam ADC multispectral cam, SPAD-502 chlorophyll meter, NDVI index

\section{$\underline{\text { A B S T R A C T }}$}

Health condition and vegetation activity are very important indicators to know the primer production of plants and fruit trees as well. There is a very close relationship between the dynamism of fruit tree development and their photosynthetic activity. Some traditional and modern instruments and methodology were used to survey vigor condition of the vegetation. We surveyed an intensive apple orchard at the Regional Research Farm of the University of Debrecen near Pallag by three spectral instruments. The spectral surveys were at the early senescent stage of the apple plantation. Investigation results were analyzed by different software environments; normalized differential vegetation index (NDVI) map was created and spectral point sampling was carried out in the test site. Spectral results were compared and strong linear correlations $(r>0.7)$ were detected between each spectral measurement. The applied instruments gave information about vigor condition of the fruit trees in a non-destructive way.

\section{Introduction}

To determine the vigor condition of vegetation is a very important factor by plant production consideration. The aim of these investigations is to minimize disturbance to naturally occurring populations. Presently, some useful instruments are available to survey the health status of agricultural plants and horticultural trees by non-invasive methods.

Today, IT provides the farmers such tools, like global positioning system (GPS), geographic information system (GIS) and remote sensing (RS) (Milla et al. 2005), which, at the same time, develop rapidly, in a great integration. Using this ternary technology at agricultural or horticultural specialty is the so-called precision agriculture (Tamás 2001).

RS, also called earth observation, refers to the obtaining of information about objects or areas at the Earth's surface without being in direct physical contact with the object or area. The basis of remote sensing is incoming electromagnetic radiation $\left(\mathrm{E}_{\mathrm{I}}\right)$ to the object. When the radiation incident upon the object's surface, it is reflected $\left(E_{R}\right)$ by that surface, transmitted $\left(E_{T}\right)$ into the surface or absorbed $\left(E_{A}\right)$ by the surface. Thus, it could be established that the reflection, absorption and transmission are equal

\author{
${ }^{1}$ Péter Riczu \\ University of Debrecen, 4032 Debrecen, Böszörményi út. 138, Hungary \\ riczu@agr.unideb.hu \\ ${ }^{2}$ Attila Nagy \\ University of Debrecen, 4032 Debrecen, Böszörményi út. 138, Hungary \\ attilanagy@agr.unideb.hu \\ ${ }^{3}$ Éva Bozsik \\ University of Debrecen, 4032 Debrecen, Böszörményi út. 138, Hungary \\ eva.bozsik@agr.unideb.hu \\ ${ }^{4}$ Bernadett Gálya \\ University of Debrecen, 4032 Debrecen, Böszörményi út. 138, Hungary \\ bernadett.galya@agr.unideb.hu \\ ${ }^{5}$ Péter Ákos Mesterházi \\ University of West Hungary, 9200 Mosonmagyaróvár, Vár utca 2, Hungary \\ mesterhazi@ikr.hu \\ ${ }^{6}$ János Tamás \\ University of Debrecen, 4032 Debrecen, Böszörményi út. 138, Hungary \\ tamas@agr.unideb.hu
}


to the total incoming radiation on a given wavelength (Aggarwal 2004). So, it could be created the equation (1):

$$
E_{R}(\lambda)+E_{A}(\lambda)+E_{T}(\lambda)=E_{I}(\lambda)
$$

Most remote sensing systems are designed to collect reflected radiation (Short 2011). The reflectance and absorbance values are depending on the physical characteristics and the geometric structure of the object (Molenaar 1993). Depending on the incoming light, remote sensing can be either passive or active. Reflected sunlight is the most common source of radiation measured by passive sensors, while active sensors emit a certain radiation, so it could be measured with these instruments in day or night.

Remote sensing is an effective tool for monitoring the biomass production and health status. By using certain reflectance values of adequate spectral bands vegetation indices can be calculated, which correlate well with the vigor. Plants reflect the visible (VIS) band in a small compass, but in the near infrared (NIR) band, the reflectance increases according to the chlorophyll content of leaves and changes proportionally to chlorophyll concentration. Using the reflection of the RED (630-690 nm) and the NIR bands (760-900 nm), a plant's green mass can be determined (Tucker, 1979). One of the most frequently used indices for investigating surface coverage and biomass is the Normalized Difference Vegetation Index (NDVI) (Rouse et al. 1973).

Many authors have investigated agricultural crops and horticultural trees with special remote sensing instruments to conclude the vigor status of plants. Flynn et al. (2008) used a special NDVImeter (GreenSeeker) to collect information and assess the spectral properties of pasture biomass. Coventry et al (2011) used GreenSeeker to establish the rate and schedule of nitrogen and water application for winter wheat.

To investigate the pigment activity of plants in a non-destructive and quick way the SPAD meter was widespread. SPAD values are correlated with the chlorophyll concentration of the leaves Campbell et al (1990) compared the chlorophyll content and the growing condition of apple's leaves. Van den Berg \& Perkins (2004) estimated chlorophyll and nitrogen content in sugar maple's leaves. Imagine sensors are effective tools for vegetation analysis, hence it could get information about the environment of investigated plants.

Other spectral imaging systems are appropriate for vegetation analysis. Lehoczky et al (2006) long term experiments were carried out by Tetracam ADC to assess the fertilization effect weed biodiversity. There are few studies, which compared different devices, which measure vegetation activity of plants, between horticultural conditions.

The aim of this study is to investigate the spatial variation canopy vigor status in an intensive apple orchard, and to compare three NDVI sensor systems.

\section{Applied methods}

The spectral surveys were carried out at the Study and Regional Research Farm of the University of Debrecen, near the town of Pallag. The study area was an intensive apple orchard with drip irrigation system, protected with a hail net. The measurements were at the early senescent stage (after the first autumn frost in this year) of the apple plantation at 01.10.2013 and 30.10.2013.

To investigate the spectral features of the whole study area, GreenSeeker 505 vegetation indexmeter was used (Figure 1). The instrument is suitable for measuring several vegetation indices, but the most information was provided by the NDVI value. Every row of the apple orchard was surveyed at both sides by the instrument. Because of the GreenSeeker 505 is an active remote sensing tool, it has got an internal light for calculating the NDVI. The sensor operates by emitting light (red band $-656 \mathrm{~nm}$ and near infrared band $-774 \mathrm{~nm}$ ) from the rectangular window onto a crop's canopy. Reflected light from the canopy is focused on a detector behind the circular window. The system calculates the NDVI from the given reflectance values, based equation (2): 


$$
N D V I=\frac{N I R-R E D}{N I R+R E D}
$$

Data collecting was carried out 50-100 cm from the foliage. As an interface of GreenSeeker 505 was working, an AgGPS FmX integrated display by Trimble, which collected the coordinate data beside the NDVI values. During the measurement EGNOS DGPS correction signal was used to achieve ca. 15-20 cm accuracy. During the whole measurement, the logging interval was one second. The acquired data was stored in the hardware of the job computer each second. Both the AgGPS FmX and the GreenSeeker 505 were mounted on a tractor. Uniform data collection was provided by the constant speed of a tractor. The raw database file from the jobcomputer was examined and analyzed it in Microsoft ExcelTM, then for the spatial analyzing, Surfer 11 software was used. To evaluate the data, an NDVI map was created using an interpolation technique. Interpolation is a mathematical approximate method to determine unknown values based on known values. The interpolation of spatial data was carried out using the Nearest Neighbor method.

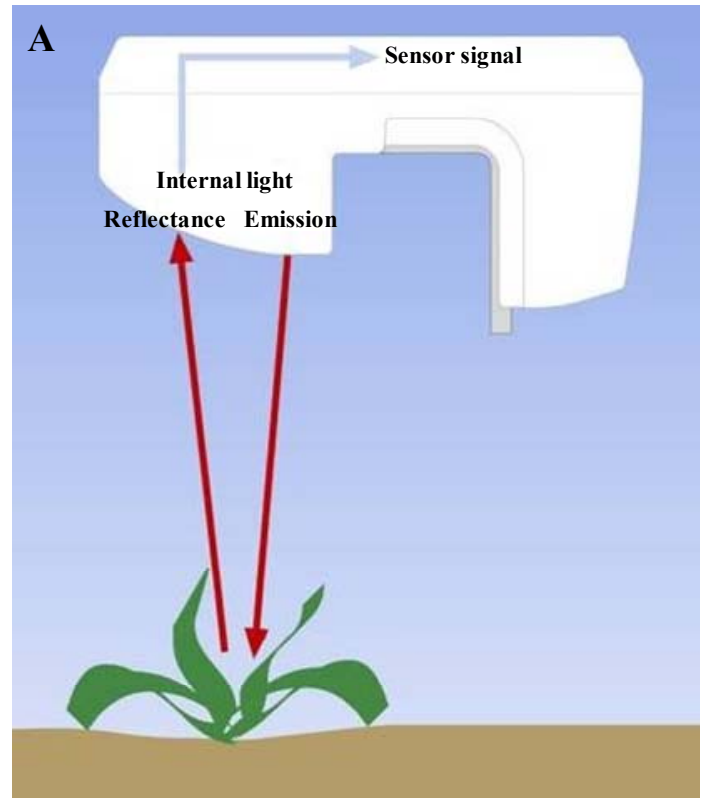

B

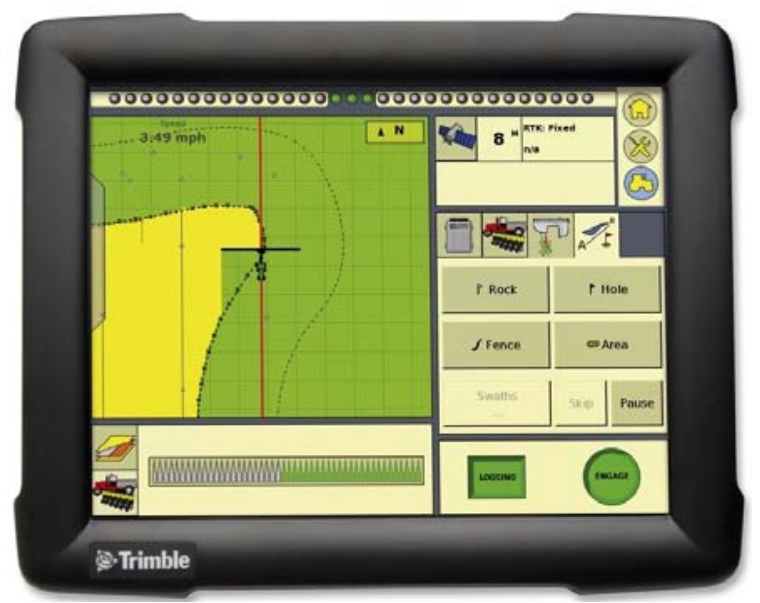

Figure 1. Working principle of GreenSeeker 505 and the AgGPS FmX Integrated Display

Source: A - Crop optics - Australia Pty Ltd.

B - Lessiter Publications and Farm Equipment

To verify the GreenSeeker NDVI map, point sampling was executed by SPAD-502 and Tetracam ADC spectral instruments. SPAD-502 (Soil Plant Analysis Development) uses red (at $650 \mathrm{~nm}$ peak point) and infrared (at $940 \mathrm{~nm}$ peak point) to measure the SPAD value. The instrument is an active remote sensor like the GreenSeeker, with similar electromagnetic sampling bands. The main difference in working principle is, that SPAD measures the absorbance of the emitted lights. SPAD values are between $0-100$; lower values indicate lower vegetation activity. 10 trees were chosen in the plot area to determine those SPAD values. The SPAD values were calculated based on 6 replications in the case of each selected tree.

At the time of the other spectral measurements, imagine point surveys were carried out by Tetracam ADC broadband multispectral passive remote sensing camera, its resolution is $1280 \times 1024$ pixel. Since the camera is a passive remote device, due to the changing weather conditions, the instruments had to be calibrated. The multispectral surveys could be provided to recognize vigor condition of the whole canopy and the neighboring fruit trees as well and even the spectral properties of one leaf could be known. The camera creates spectral reflectance images in three bands (green $520-600 \mathrm{~nm}$, red $-650-750 \mathrm{~nm}$ and infrared $-750-950 \mathrm{~nm}$ ). Based on the reflectance values, vegetation indices could be created in PixelWrench2 software environment, which is the main 
software of Tetracam ADC. In the basic software, red, near infrared and NDVI images were created. Only one smaller part of each image was exported in TIF format for pixel-based post-processing to avoid interfering effect of the soil, trunk and sky pixels. For further data mining, IDRISI Taiga software by Clark Labs was used. To prepared NDVI images, red and NIR images were combined in this software.

\section{Major research results}

The collected data by the GreenSeeker 505 were processed and evaluated in Surfer 11 software environment. One week after the first frost in this autumn, the pigment synthesis of leaves began to change. The average middle range (0.566) NDVI values are indicated in Figure 2. During the 30 days, there wasn't further frost, so chlorophyll in the leaves decreased slowly (NDVI=0,509).

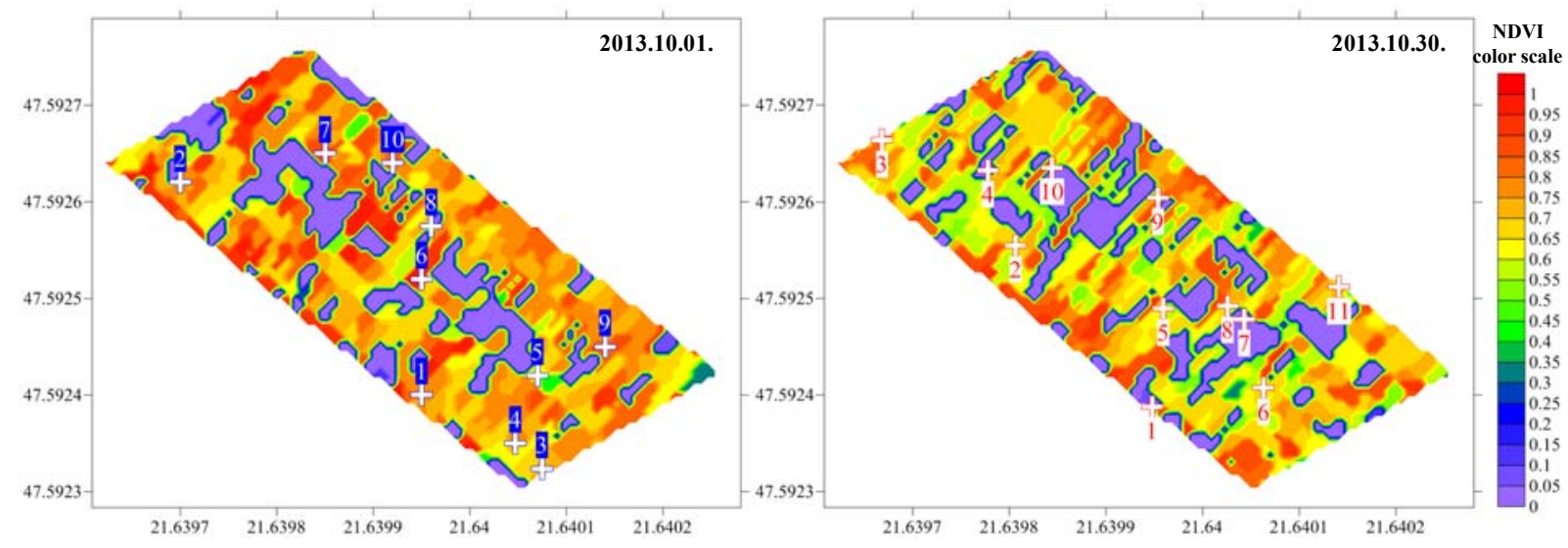

Figure 2. Interpolated GreenSeeker-NDVI map of the investigated area with sampling points of SPAD-502 and Tetracam ADC measurements in Surfer 11 software environment

Due to a microbiological disease (Fire Blight - Erwinia amylovora) some apple trees were infected and died in the investigated orchard in the last summer (in the term of July, 2012). The purple areas show, where the trees were died.

GreenSeeker NDVI values and point sampled SPAD values were compared (Figure 3), and it could be detected a strong positive correlation between the investigated variables at the early November $(\mathrm{r}=0.782)$ and the late November $(0.73)$ measurements. 


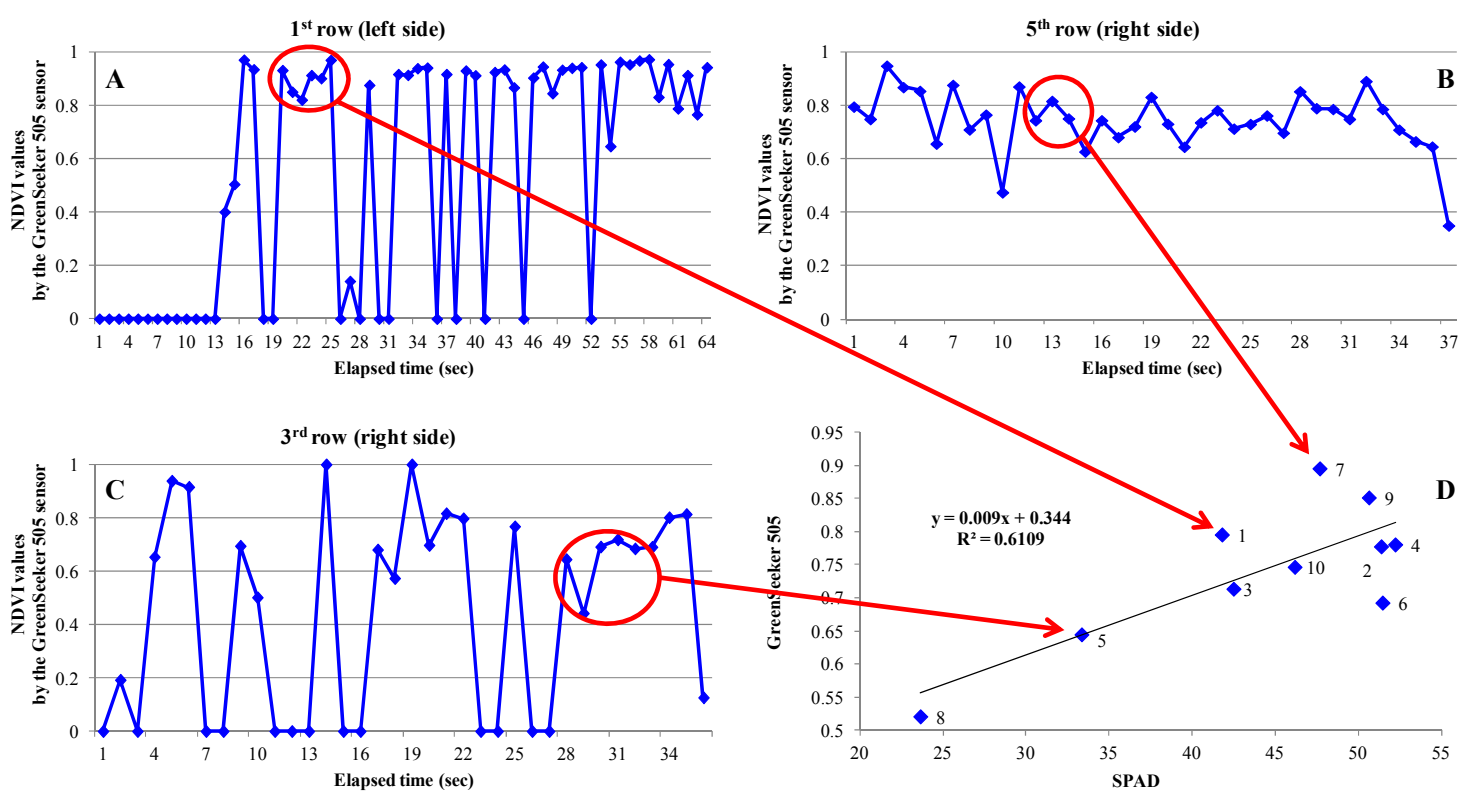

Figure 3. Curve analysis of the course of AgGPS FmX, GreenSeeker 505 (A, B, C), and the correlation between NDVI and SPAD values (D) at $1^{\text {st }}$ November, 2013

In our examinations, multispectral images were evaluated. As a first step, the NDVI values from PixelWrench2 and IDRISI were compared. It could be determined that the NDVI values, which were created in IDRISI, were higher than PW2-NDVI values (Figure 4). The average difference between the two software evaluations was 0.093 ; nevertheless between the two calculated NDVI values, a close correlation $(\mathrm{r}=0.96)$ could be established.

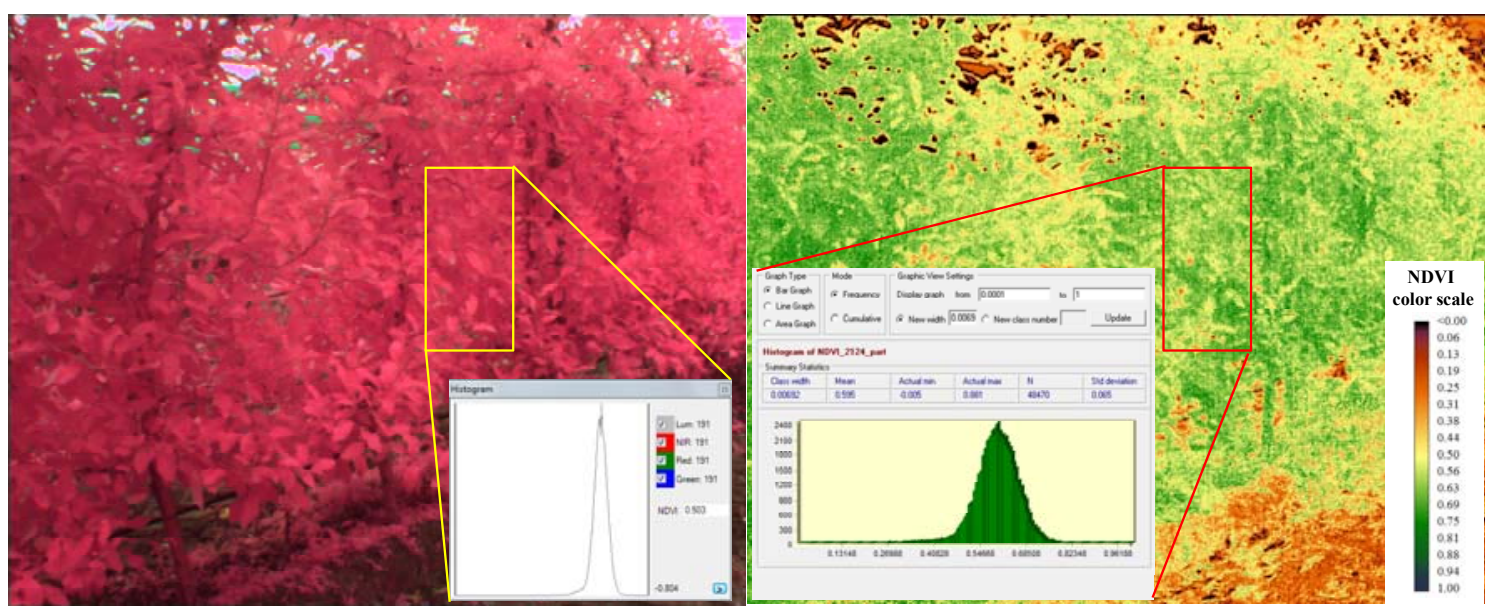

Figure 4. An example of a raw false color image (A) in PixelWrench2 and NDVI color image (B) in IDRIS software environment with the NDVI-histograms of highlighted rectangles.

Comparing the NDVI values by the GreenSeeker and the NDVI values of a given rectangle area by the Tetracam ADC at the two surveys, a high correlation could be detected $(\mathrm{r}=0.766)$. Tetracam-NDVI and SPAD values showed even a higher correlation $(r=0.856)$.

\section{Conclusions}

The intensive apple orchard was surveyed with three remote sensing instruments to investigate the spectral properties of the canopy in the early senescent phenological stage of trees. Combination of the devices, a complex vegetation analysis could be elaborated. The GreenSeeker-GPS system is a useful 
tool for mapping vegetation conditions, which is one of the most important elements of the sitespecific agriculture and horticulture practice. The multispectral camera was effective to define NDVI values of the full canopy or even of that of one leaf. Point samplings were carried out by the SPAD502 chlorophyll meter. Based on the result, the used instruments are appropriate to establish the vigor and health condition of the vegetation. Measurement results of the instruments were compared and in each case a high correlation of them was detected $(r>0.7)$.

The vegetation analyses are suitable for monitoring the whole plantation, and the vegetation indexes could help to provide the best or most rational horticultural practice. In the future, based on the NDVI values a precision nutrient management, chemical and energy saving spraying system could be elaborated.

\section{Acknowledgements}

This research was realized in the frames of TÁMOP 4.2.4. A/2-11-1-2012-0001 „National Excellence Program - Elaborating and operating an inland student and researcher personal support system". The project was subsidized by the European Union and co-financed by the European Social Fund.

\section{References}

Aggarwal S. 2004. Principles of Remote Sensing. [In. Sivakumar M V K, Roy P S, Harsen K, Saha S K. (eds.): Satellite Remote Sensing and GIS Applications in Agricultural Meteorology.] World Meteorological Organisation, Geneva. 23-38 p.

van den Berg A K, Perkins T D. 2004. Evaluation of a portable chlorophyll meter to estimate chlorophyll and nitrogen contents in sugar maple (Acer saccharum Marsh.) leaves. Forest Ecology and Management. 200 vol 1-3. pp 113-117.

Coventry D R, Yadav A, Poswal R S, Sharma R K, Gupta R K, Chhokar R S, Gill S C, Kumar V. Kumar A, Mehta A, Kleemann S G L, Cummins J A. 2011. Irrigation and nitrogen scheduling as a requirement for optimising wheat yield and quality in Haryana, India. Field Crops Research. 123 vol 2. pp 80-88.

Flynn E S, Dougherty C T, Wendroth O. 2008. Assessment of pasture biomass with normalised difference vegetation index from active ground-based sensors. Agronomy Journal. 100 vol 1.pp 114-121.

Lehoczky É, Tamás J, Kismányoki A, Burai P. 2006. Comparative study of fertilization effect on weed biodiversity of long term experiments with near field remote sensing methods. Journal of Plant Diseases and Protection. 801-807 p.

Milla K A, Lorenzo A, Brown C. 2005. GIS, GPS, and remote sensing technologies in Extension services: Where to start, what to know. Journal of Extension [On-line]. 43 vol 3. Available at: http://www.joe.org/joe/2005june/a6.php

Molenaar M. 1993. Remote Sensing as an Earth Viewing system. [In: Buiten H J, Clevers J G P W. (eds.): Land Observation by Remote Sensing - Theory and Applications.] Overseas Publishers Association, Amsterdam. 27$36 \mathrm{p}$.

Campbell R J, Mobley K N, Marini R P, Pfeiffer D G. 1990. Growing conditions alter the relationship between SPAD-501 values and apple leaf chlorophyll. HortScience. 25 vol 3. pp 330-331.

Rouse J W, Haas R H, Schell J A, Deering D W. 1973. Monitoring Vegetation Systems in the Great Plains with ERTS. Third ERTS Symposium, NASA SP-351 I., pp 309-317.

Short N M. 2011. The Remote Sensing Tutorial. Available at: http://rst.gsfc.nasa.gov

Tamás J. 2001. Precíziós mezőgazdaság. [Precision agriculture.] Mezőgazdasági Szaktudás Kiadó. Budapest. 144. p.

Tucker C J. 1979. Red and Photographic Infrared Linear Combinations for Monitoring Vegetation. Remote Sensing of the Environment 8., pp 127-150. 